\title{
A Proteção Legal do Nome da Pessoa Natural no Direito Brasileiro
}

\section{Arthur Maximus Monteiro}

Mestrando em Direitos Fundamentais pela Universidade de Lisboa. Pós-graduado em Direito Processual Givil pela UECE/FESAC. Advogado. arthurmaximus@bol.com.br

Sumário: Introdução. 1. Direito ao nome.

2. Proteção jurídica do nome. Referências.

Resumo: Neste artigo procuraremos analisar os principais aspectos relacionados ao nome da pessoa natural no direito brasileiro. O primeiro problema diz respeito à própria delimitação da matéria: o que se entende por direito ao nome? Afastando figuras correlatas que possuem a mesma origem - a personalidade -, a pesquisa centrar-se-á no exame dogmático da matéria. Serão definidos: 1 - os elementos constitutivos do nome; 2 - o que se entende por pseudônimo; 3 - qual é a proteção jurídica dispensada pelo nosso ordenamento ao nome, seja no campo penal, seja no campo civil.

Palavras-chave: Direito privado. Direitos da personalidade. Direito ao nome.

\section{NTRODUÇÃO}

A ciência jurídica possui natureza intrinsecamente conservadora. Entenda-se: seja-se organicista ou contratualista, é inequívoco concluir que o Estado existe para manter e conservar um determinado status quo. E o instrumento utilizado para manter e conservar uma determinada ordem das coisas é precisamente o Direito.

Cuida o Direito de estabelecer regras de conduta que permitam aos seres humanos conviverem com um mínimo de harmonia. Daí porque, se há um só sujeito, não há Direito; o Direito pressupõe o mínimo de dois sujeitos a se relacionarem para então surgir e aplicar-se.

O estabelecimento, a conservação e a reparação de relações sociais é a função última do sistema jurídico. Seu pressuposto é, pois, a existência de uma sociedade - ou, mais especificamente, de uma pluralidade de indivíduos - cujas relações o Direito pretende regular. 
Mas, para que os indivíduos possam relacionar-se, é indispensável que se identifiquem. É natural que busquem diferenciar-se uns dos outros não somente por sinais físicos, mas também por sinais distintivos. É parte da natureza humana, portanto, atribuir-se um nome ${ }^{1}$.

É o nome o primeiro bem jurídico associado à pessoa. É por ele que o sujeito se individualiza perante os demais. É o símbolo gráfico e fonético pelo qual a pessoa será conhecida por toda sua existência, e mesmo depois dela. É, talvez, aquilo que lhe é mais próprio e caro, a tal ponto que não exageraríamos se disséssemos que chega a se confundir com a própria personalidade individual.

Embora intuitivamente já se pudesse pensar que a ordem jurídica protegia o nome como verdadeiro bem jurídico da pessoa, foi com o Novo Código Civil que esse direito foi definitivamente incorporado ao ordenamento nacional.

\section{DIREITO AO NOME}

Antes de entrarmos na controvérsia doutrinária acerca do direito ao nome, é necessário estabelecer precisamente do que se trata.

O direito a o nome não é o mesmo que o direito de dar um nome. $\mathrm{O}$ primeiro é próprio do indivíduo; o segundo, dos pais. Como lembra Venosa, "ao nascermos, ganhamos um nome que não tivemos a oportunidade de escolher" (Venosa, 2006, p. 185). E não o tivemos porque o direito de escolha do nome é, em princípio, dos pais, e não do indivíduo. Este tem o direito de receber e possuir um nome; mas a escolha do nome é algo que,

\footnotetext{
' A necessidade de identificar-se é problema que não escapa sequer aos poetas. É o caso, por exemplo, de João Cabral de Melo Neto, célebre poeta pernambucano, autor do clássico da literatura brasileira M orte e Vida Severina: um auto de natal pernambucano. No primeiro capítulo, logo em seu início, a personagem principal - Severino - indaga-se como apresentar-se à plateia:

"O meu nome é Severino, não tenho outro de pia.

Como há muitos Severinos, que é santo de romaria, deram então de me chamar Severino de Maria; como há muitos Severinos, com mães chamadas Maria, fiquei sendo o da Maria do finado Zacarias.

Mas isso ainda diz pouco: há muitos na freguesia, por causa de um Coronel que se chamou Zacarias e que foi o mais antigo senhor desta sesmaria.

Como então dizer quem fala ora a Vossas Senhorias?

Vejamos: é o Severino da Maria do Zacarias lá da Serra da Costela, limites da Paraíba.

Mas isso ainda diz pouco: se ao menos amais cinco havia, com nomes de Severino, filhos de tantas Marias, mulheres de outros tantos, já finados, Zacarias, vivendo na mesma serra magra e ossuda em que eu vivia".
} 
em princípio, não lhe cabe, mas aos seus ascendentes. Tanto é assim que somente nos casos autorizados em lei o sujeito pode alterar seu nome. A escolha dos pais, em princípio, é definitiva e insusceptível de mudança.

A rigor, cuida-se não somente de um direito, mas também de um dever. Tem-se, na verdade, um poder-dever dos pais quanto à escolha do nome do filho. Mas não se trata, obviamente, de um direito absoluto. A própria lei estabelece balizas para a escolha do nome no ordenamento brasileiro. Os pais não podem, por exemplo, atribuir ao filho um nome que o sujeite ao ridículo. A despeito de essa posição não ser pacífica (Pontes de Miranda, 2000, p. 305), cremos ser ela mais consentânea com o regramento positivo existente no direito brasileiro.

É importante destacar, também, que o direito ao nome não se confunde com o direito à honra, à reputação e ao bom nome (Dray, 2006, p. 41/42). Conquanto os demais também sejam direitos da personalidade, com ele não se confundem. Tratam, na verdade, de aspectos diversos da personalidade do indivíduo, relativos ao conceito que a sociedade e o próprio indivíduo faz de si mesmo. Não cuidam, propriamente, do direito de individualizar-se perante os demais (Carvalho, 1972, p. 37).

\subsection{CONCEITO DE NOME}

As definições de nome são tão variadas quanto o próprio tema. Afirma-se, com frequência, que o nome é um sinal distintivo do sujeito, que serve para diferenciá-lo de seus semelhantes (De Cupis, 1950, p. 139; Venosa, 2006, p. 185). Há ainda os que relacionam o nome à identificação da ascendência - materna, paterna ou ambas - do ser humano (Pereira, 1998, p. 155). Mas isso ainda não nos diz precisamente o que é o nome.

Dizer-se que o nome serve para identificar o sujeito, ou mesmo para indicar sua origem familiar, não é propriamente um conceito de nome ${ }^{2}$, mas a sua função. Além disso, há ainda de se lembrar que o nome designa não somente pessoas, mas coisas inanimadas, animais, lugares e mesmo apenas ideias (Coelho, 1953, p. 168).

\footnotetext{
${ }^{2}$ Sobre esse aspecto, é inevitável não recordar Julieta, uma Capuleto, a expressar sua frustração pelo fato de não poder amar um integrante da casa dos Montecchios, em razão do ódio existente entre as duas famílias:

"' $T$ is but thy name that is my enemy;

T hou art thyself, though not a $M$ ontague.

W hat's M ontague? it is nor hand, nor foot, nor arm, nor face, nor any other part belonging to a man.

0 , be some other name! W hat's in a name?

T hat which we call a rose by any other name would smell as sw eet;

So R omeo w ould, werehe not R omeo call'd, retain that dear perfection which he owes without that title.

R omeo, doff thy name, and for that name which is no part of thee take all myself".

SHAKESPEARE, William. R omeo and J uliet. Act II, Scene 2.
} 
Antes de mais nada, o nome é um sinal gráfico ou fonético ${ }^{3}$. Gráfico, porque normalmente expresso na forma escrita. Fonético, porque à escrita corresponde um certo modo ou forma de pronúncia, a identificar oralmente o indivíduo ${ }^{4}$ Estabelecido o sinal, atribui-se-lho a um sujeito. E é dessa atribuição que, então, o nome passa a manifestar seu traço distintivo. O conceito, pois, precede a função, e não o contrário.

Os hebreus costumavam ter apenas um nome (Moisés, Jacó, Davi). Com o tempo, com a pluralidade de indivíduos, foram acrescentando outros nomes para diferenciarem-se uns dos outros. Esses nomes ordinariamente designavam ou a origem topográfica ou mesmo a profissão do sujeito. Daí Iesus Nazarenus - Jesus de Nazaré, porque provindo de família radicada em Nazaré, na Judeia. Pela mesma razão, João tornou-se Batista, para designar o oficio que lhe fora encarregado por Deus: batizar toda a gente ${ }^{5}$.

Os gregos, por sua vez, identificavam os seus com dois nomes, mas foram pioneiros ao acrescentar um terceiro nome ao nome da pessoa. $\mathrm{O}$ primeiro - prenome, como nome próprio; o segundo, o nome patronímico, identificando a origem familiar; e o terceiro, gentílico, identificando o nome de toda a gens. Como tudo na sociedade romana remetia à Grécia, os romanos também adotaram o estilo de identificação com três nomes.

Com a invasão dos bárbaros e a queda de Roma, retornou-se ao costume do nome único. Na Idade Média, por influência da Igreja Católica, passou-se a atribuir às pessoas nomes de santos. Daí porque o calendário católico atribuía a cada dia um santo, de modo a “orientar" os fiéis quanto à escolha dos nomes dos filhos (Venosa, 2006, p. 187/188).

Mas, evidentemente, o tempo trouxe consigo novamente a necessidade de diferenciação dos nomes dos sujeitos. Voltou-se, pois, a precisar de sobrenomes para diferenciar uns dos outros. As referências eram as mesmas da antiguidade: origem de nascimento (Borgonha) e profissão (Ferreiro) (Baudry-Lancatinerie e Houques-Fourcade, 1907, p. 278). O expurgo dos judeus e o aparecimento dos cristãos novos fez surgir os sobrenomes ligados a animais (Coelho) e plantas (Pinheiro) (De Cupis, 1950, p. 145).

3 A partícula alternativa justifica-se na medida em que a escrita nem sempre acompanhou a humanidade. Hodiernamente, é fato que na maioria das sociedades a todo nome corresponde uma representação gráfica, cuja forma é designada pelo alfabeto ao qual o povo do indivíduo está vinculado (grego-romano, cirílico, ideogramático etc). Mas nem sempre assim o foi. Além disso, a escrita é a última forma de inter-relacionamento humano. Precedem-na a expressão corporal e, obviamente, a expressão oral.

${ }^{4} \mathrm{O}$ caráter fonético possui ainda mais relevo do que o gráfico especialmente nos idiomas tonais, como o mandarim, o coreano e o japonês. Uma mesma representação ideogramática pode ter "n" possibilidades de pronunciação, e a cada qual corresponderá uma ideia ou, mais apropriadamente, um nome diferente.

5 É curiosa, nesse aspecto, a análise da Bíblia. No Velho Testamento, especialmente nos livros do Pentateuco, aos sujeitos é atribuído um único nome: Adão, Eva, Abraão, Sara, Moisés etc. Já no Novo Testamento, abundam os casos de sujeitos com dois nomes: Jesus de Nazaré, João Batista, Saulo de Tarso etc. É evidente que esse acréscimo não deriva unicamente da Providência Divina, mas retrata mesmo a evolução histórica da identificação dos sujeitos. 
Atualmente, existem três grandes sistemas de denominação das pessoas (Carvalho, 1972, p. 19): o sistema árabe e eslavo, no qual, além do prenome, predominam designações de qualidade e procedência da pessoa (Raynaud, 1976, p. 798); o sistema europeu, no qual há apenas a obrigatoriedade de um único nome próprio e outro, familiar (em geral o paterno); e o sistema peninsular, adotado na península ibérica e em grande parte dos países colonizados por Portugal e Espanha, no qual, ao lado do nome próprio, figuram os nomes familiares materno e paterno.

No Brasil, como se sabe, adota-se o sistema peninsular: a par do prenome, seguem-se normalmente os nomes familiares indicativos da ascendência materna e paterna.

Surge, então, o problema da classificação e identificação das partículas integrantes do nome. $\mathrm{O}$ que se entende por nome propriamente dito? O que serão o prenome, o sobrenome, o nome patronímico e o agnome? É o que veremos a seguir.

\subsection{ELEMENTOS CONSTITUTIVOS DO NOME}

Por nome entende-se o conjunto de vocábulos gramaticais que representam, gráfica ou foneticamente, determinado indivíduo (Capelo de Sousa, 1995, p. 250). Na Antiguidade e em grande parte da Idade Média, como vimos, o nome era composto por uma única partícula: o nome próprio. $\mathrm{O}$ acréscimo de designações de família, ofício ou lugar foram integrando-se ao nome e ganhando as mais diversas denominações. Todavia, há séria divergência quanto às definições precisas dos elementos constitutivos do nome. O próprio Código Civil de 2002 estabelece a distinção ${ }^{6}$, sem, contudo, definir precisamente quais são os elementos do nome. É necessário, portanto, procurar sistematizar e definir de forma clara tais elementos a fim de não nos confundirmos na análise da matéria.

O primeiro desses elementos constitutivos é o chamado prenome. É talvez o único dos elementos integrantes do nome sobre o qual não pairam grandes dúvidas.

Prenome é o primeiro nome, o vocativo pelo qual normalmente designa-se o sujeito. É a parte do nome que efetivamente lhe é própria e destinada a identificá-lo e diferenciá-lo como indivíduo, à diferença dos demais elementos constitutivos, destinados a identificar a sua origem familiar ou gentílica. Não é por outra razão que o prenome também é conhecido por nome próprio.

\footnotetext{
${ }^{6}$ Cf. "Art. 16. Toda pessoa tem direito ao nome, nele compreendidos o prenome e o sobrenome".
} 
Em "José Ferreira da Silva", por exemplo, "José” é o prenome ou nome próprio. Enquanto "Ferreira da Silva" designa a sua origem familiar - e isso estava posto antes mesmo de o sujeito ser concebido - "José" é o elemento que o distingue dentre os seus. Pode haver muitos irmãos, tios, sobrinhos e primos, mas, na família Ferreira da Silva, somente ele é "José"."

Os romanos adotavam estrutura semelhante (Coelho, 1953, p. 169). Em $M$ arcus Tulius Cícero, isso representava um indivíduo chamado Marcos, da gente dos Túlio, da família Cícero ${ }^{8}$. Cada partícula do nome servia a um propósito, e o propósito do prenome não era outro senão de diferenciar o sujeito dentre os membros de sua própria família.

O prenome pode ser simples ou composto. Simples, quando constituído por uma única partícula; composto, quando a este se sobrepuserem uma ou mais de uma9 ${ }^{9}$ Nos exemplos acima, temos claramente prenomes simples: José e Marcos. Mas abundam casos de prenomes compostos: Júlio César, João Luiz, Ana Maria, Maria Paula etc. $\mathrm{E}$ - mais que isso - não são raros os casos de prenomes compostos por nomes que, individualmente, representam gêneros diferentes: José Maria, Maria João etc.

No entanto, para além de sua função primária - de distinção do indivíduo - o nome também possui a função de relacionar o sujeito à família de que provém (Coelho, 1953, p. 169). Daí a importância do sobrenome.

Por sobrenome entende-se tudo aquilo que se acresce ao prenome. Costuma-se também designar o sobrenome de apelido, nomepatronímico ou mesmo nome de família.

Verdadeiramente, o sobrenome precede o prenome em sua origem. Desde antes de sua concepção, o sujeito está destinado a levar consigo o nome de seus pais. É, na verdade, uma decorrência natural de pertencer a uma família. A atribuição do prenome pressupõe, antes, a determinação do nome familiar (Raynaud, 1976, p. 798).

\footnotetext{
${ }^{7}$ Registre-se que aqui se cuida de traço distintivo relativo à diferenciação do sujeito dentro da própria família. Não se pretende com isso defender ou entender que há um direito à exclusividade do nome. Tal direito não há, nem poderia haver.

${ }^{8}$ Mas isso era privilégio dos patrícios. Os escravos e a plebe tinham um nome, ou no máximo dois, quando o segundo decorria do prenome do dono.

${ }^{9}$ Era costume nos séculos XVIII e XIX atribuírem-se uma quantidade imensa de prenomes aos sujeitos, especialmente quando membros da nobiliarquia. É clássico o exemplo de Dom Pedro I (ou Dom Pedro IV, em Portugal), cujo nome completo era Pedro de Alcântara Francisco António João Carlos Xavier de Paula Miguel Rafael Joaquim José Gonzaga Pascoal Cipriano Serafim de Bragança e Bourbon. Talvez por isso mesmo a legislação portuguesa tenha restringido a quantidade de nomes a serem atribuídos a uma pessoa: dois, no caso de nome próprio; quatro, no caso de sobrenome. Cf. art. 128, nº 1, do Código de Registo Civil Português.
} 
Há doutrinadores que preferem chamar o sobrenome de nome patronímico. A rigor, a identidade é falsa, porque patronímicos são somente os sobrenomes que se formam com desinência de genitivo para indicar a filiação do sujeito (Pontes de Miranda, 2000, p. 304). É o caso, por exemplo, de Domingues, para identificar o filho de Domingos; Fernandes, para identificar o filho de Fernando; Henriques, para identificar o filho de Henrique $^{10}$. No entanto, a associação ganhou curso, e hoje não raro tem-se doutrinadores e operadores do direito a apontar como patronímico todo e qualquer vocábulo que designe a ascendência familiar do indivíduo.

Fala-se, além do sobrenome, na existência do agnome.

Por agnome, entende-se todas as partículas que vêm após o nome familiar, com o fim de designar alguma qualidade particular ou característica do sujeito, ou ainda, nos casos de homonímia familiar, a diferenciar sujeitos dentro de sua própria família. São agnomes, pois: Magno, Grande, Júnior, Filho, Neto, Sobrinho, Segundo etc. Foram os romanos os primeiros a adotá-lo. Sua função ia além da individualização do sujeito, mas quase sempre servia à exaltação de imperadores ou comandantes militares. Daí Alexandre, o Grande e Cipião, o Africano.

Mas, como dito, os agnomes podem servir não só para designar qualidades na acepção positiva da palavra. Podem também indicar traços negativos da personalidade (Pedro, o Cruel, rei de Portugal), ou mesmo a baixa estatura de um governante (Pepino, o Breve).

Nos termos da redação do art. 16 do Novo Código Civil, podemos afirmar que a lei reconhece três elementos: nome, prenome e sobrenome. Há quem possa entender que, em verdade, apenas os dois últimos são reconhecidos como partículas integrantes do nome, sendo este entendido apenas em seu conjunto. Não negamos que se possa dar sentido global ao termo "nome", de modo a abarcar todo o direito a ele referido. Por outro lado, é regra elementar de hermenêutica que a lei não contém palavras inúteis. Assim, além de o termo "nome" constituir a designação pela qual o legislador refere-se ao conjunto de vocábulos gramaticais representativos do nome do sujeito, podemos também afirmar que o "nome", como tal, é um elemento do nome em seu conjunto. Desse modo, com base no que há no art. 16 do Código Civil e as disposições da Lei no 6.015/73, entendemos que a sistematização pode dar-se da seguinte forma:

1 - Prenome, ou nome próprio: vocábulo que identifica e diferencia o sujeito perante a sua própria família e gente;

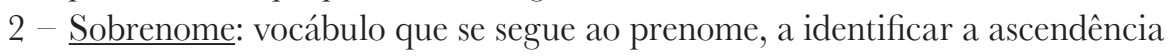
familiar materna;

\footnotetext{
${ }^{10} \mathrm{E}$ como não nos lembrarmos dos patronímicos anglo-saxões? "Mc", no caso da língua inglesa - D ouglas M cArthur, Douglas filho de Arthur; e "Von", no caso da língua alemã - F riedrich Carl Von Savigny.
} 


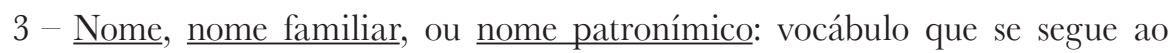
sobrenome, a identificar a ascendência familiar paterna.

4 - Agnome: partícula que se segue às demais, a designar uma característica ou qualidade particular do sujeito, ou, ainda, a diferenciar, em casos de homonímia, sujeitos de uma mesma família.

Além da classificação dos elementos integrantes do nome, a ordem de aparição dos vocábulos também gera confusões. Na tradição europeia havia uma ordem de aparição dos nomes indicativos da ascendência materna e paterna. Entendia-se, então, que, quanto mais próximo do prenome, mais honroso o lugar. Daí porque, à época, o primeiro nome indicado era o do pai. À mãe restava o último assento (Carvalho, 1972, p. 93). Com o passar dos tempos, essa tradição foi invertendo-se, passando o nome do pai a ocupar o último lugar. A mudança tópica deu-se por obra da disseminação dos costumes inglês e francês, segundo os quais somente o último nome era transmitido aos descendentes. Logo, a manter-se a ordem até então adotada, os filhos passariam aos seus descendentes somente nome materno, e não o paterno, como se entendia que deveria ser.

Com a Constituição Federal de 1988 e as novas disposições da Lei de Registros Públicos (6.015/73), permitiu-se que os pais escolhessem quais dos nomes de suas respectivas ascendências desejavam passar adiante. A ordem também passou a ser desimportante: tanto o nome do pai como o nome da mãe poderiam vir em último lugar. Cabe aos pais a escolha dos nomes e sua ordem de aparição do nome do filho.

A despeito do interesse teórico, é importante destacar que o nome - todo ele, seja em que ordem for - é juridicamente protegido, independentemente da classificação ou sistematização que se venha a adotar. É passível, pois, de tutela em caso de violação.

\subsection{PSEUDÔNIMO}

Mas não é somente o nome que é objeto de proteção pela norma. Há outro elemento de identificação que se associa à pessoa, mas que constitui elemento integrante do nome em seu sentido estrito. Trata-se do pseudônimo.

A etimologia da palavra traduz o seu sentido: do grego pseudo = falso; nomos $=$ nome. Ou seja: pseudônimo é um "nome falso". "Falso" - entenda-se - não no sentido pejorativo do termo, mas porque não integra o nome stricto sensu, o seu nome de registro. Trata-se de um vocábulo representativo do indivíduo, atribuído por si ou por outrem, pelo qual o indivíduo diferencia-se no seu meio social.

Com efeito, o pseudônimo serve ao indivíduo como substituto do próprio nome, e não como partícula ou elemento a ser-lhe somado (Coelho, 1953, p. 177). Como, em regra, é o próprio indivíduo que escolhe seu pseudônimo (Voirin, 1970, p. 22), é comum que a ele se afeiçoe mais do que ao seu próprio nome. Às vezes por 
razões estéticas; outras, por razões sentimentais. Mas o caso mais comum é que o sujeito adote um pseudônimo por razões puramente comerciais ${ }^{11}$.

Por tais razões é que, não raro, o pseudônimo sobrepõe-se ao próprio nome do indivíduo no que toca à identificação do sujeito. Os casos são inúmeros: desde atletas (Pelé - Édson Arantes do Nascimento), passando por atores (Lima Duarte - Ariclenes Venâncio Martins; Susana Vieira - Sônia Maria Vieira Gonçalves; Fernanda Montenegro - Arlette Pinheiro Esteves da Silva); e também autores (Stendhal - HenriMarie Beyle; George Orwell - Eric Arthur Blair), e tantos outros.

Os pseudônimos artísticos são, talvez, a hipótese mais comum de pseudônimos protegidos juridicamente. Mas não são os únicos. Há casos em que não há propriamente um pseudônimo, mas um heterônimo.

Heterônimo constitui, à primeira vista, um nome como outro qualquer. Seu traço distintivo é que ao heterônimo não corresponde uma pessoa factual. Trata-se de nome atribuído por um sujeito que já possui nome próprio a um alter ego seu. Não passa, portanto, de um nome fictício atribuído a uma personagem ${ }^{12}$.

À diferença do pseudônimo, o heterônimo não é associado diretamente à pessoa. Em regra, a natureza etérea do heterônimo mantém-se sigilosa, muitas vezes por razões pessoais; em outras, por questões de segurança ${ }^{13}$. Mas, nem por isso as obras "criadas" pelos heterônimos estão à margem de proteção jurídica. $\mathrm{O}$ criador do heterônimo pode perfeitamente exercer os direitos de seu alter ego como direitos seus. Basta revelar e comprovar que o heterônimo não existe e que é ele o verdadeiro autor das obras.

O pseudônimo, desde que adotado para atividades lícitas, goza da mesma proteção conferida pela lei ao nome ${ }^{14}$. Trata-se de extensão natural da proteção do direito ao nome. Ora, se o direito ao nome implica a proteção aos símbolos gráficos e fonéticos pelo qual a pessoa é identificada, da mesma forma deve assim se proceder quanto a outros vocábulos pelos quais se identifica a pessoa. U bi eadem ratio, ibi eadem legis dispositio.

Mas, para que tenha lugar a proteção ao pseudônimo, não basta simplesmente usá-lo uma vez. É indispensável que seja notório, de modo que toda gente saiba e relacione o pseudônimo à verdadeira pessoa que se oculta por trás dele (Gonçalves, 1929, p. 222).

${ }^{11}$ Talvez a indústria fonográfica entendesse difícil produzir discos de um grego cujo nome é Geórgios Kyriácos Panayiótou. Mais fácil seria comercializar sua música adotando-se um nome de raiz inglesa: G eorge M ichael.

${ }^{12}$ Fernando Pessoa era pródigo em atribuir a pessoas imaginárias obras suas. Algumas de suas mais belas passagens têm a autoria de Álvaro de Campos, Ricardo Reis ou mesmo Bernardo Soares, pessoas que jamais existiram factualmente, senão na própria mente de seu criador.

${ }^{13}$ Daí porque Chico Buarque, perseguido pela ditadura militar no Brasil e praticamente impedido de comercializar sua música, criou o heterônimo Julinho d’Adelaide, com o qual escreveu sucessos como Joana Francesa, até que o heterônimo foi revelado e a música, censurada.

${ }^{14}$ Cf. Código Civil de 2002: "Artigo 19. O pseudônimo adotado para atividades lícitas goza da proteção que se dá ao nome". 
Convém não confundir o pseudônimo com os popularmente conhecidos apdidos ${ }^{15}$, também chamados de alcunha, epíteto ou hipocorístico (Carvalho, 1972, p. 76). Estes são formas afetivas ou pejorativas de se tratar alguém. Muitas vezes, o apelido nasce de uma desinência diminutiva ou aumentativa do nome (Zezinho, Marcão etc.). Outras vezes, o apelido surge em razão de alguma característica física do sujeito (Careca, Baleia, Negão) ou mesmo de algum episódio marcante da vida do indivíduo (Fujão).

Em certos casos, especialmente quando o sujeito adquire notoriedade, o apelido também pode ser objeto de proteção tanto quanto o nome. No Brasil, tem-se o exemplo de Jô Soares (José Eugênio Soares), humorista e apresentador de renome, cujo primeiro vocábulo deriva da abreviação afrancesada de seu primeiro nome.

Postas essas considerações introdutórias, passemos a analisar qual é a natureza jurídica do direito ao nome.

\section{PROTEÇÃO JURÍ DICADO NOME}

O nosso ordenamento, seguindo a linha clássica da tripartição dos poderes ${ }^{16}$, concedeu a um órgão específico a função de exercer, preponderantemente, a atividade jurisdicional. Esse órgão é, pois, o Judiciário.

A Constituição Federal, rompendo com paradigmas inaceitáveis de restrição de tutela de direitos existentes no ordenamento anterior - fruto de regime de exceção -, estabeleceu o amplo e ilimitado acesso dos indivíduos ao Poder Judiciário. Garante-se não somente a atuação punitiva e reparatória, decorrente da inobservância de regras de conduta, mas, também, a própria garantia de impedir que a lesão se consume, mediante atuação preventiva e inibitória. Ou, nas palavras do legislador constituinte originário, o Poder Judiciário pode e deve atuar para reparar a "lesão", mas também deve impedir que se concretize a "ameaça a direito"17.

Vendo-se o ordenamento como uma sucessão de círculos concêntricos, cujo centro de irradiação é a dignidade da pessoa humana, é evidente que a tutela dos direitos dela decorrentes assume posição de destaque (Viana e Monteiro, 2009, p. 53). E assim também deveria ocorrer com o nome. Mas não é isso o que se vê no ordenamento jurídico brasileiro.

\footnotetext{
${ }^{15}$ Não confundir com o termo apelido adotado pelo ordenamento português , e o apellido, do ordenamento espanhol. Em ambos, o termo serve a designar o que nós chamamos de nome familiar ou patronímico. Não há razão para confundir o termo com outras designações constantes no direito comparado.

${ }^{16}$ Mais apropriadamente, tripartição das funções estatais, dado que o poder é uno.

${ }^{17}$ Cf. Artigo 5º inciso XXXV, da Constituição Federal de 1988.
} 
Na sua redação original, o Código Penal previa um tipo específico de "usurpação de nome ou pseudônimo alheio". Neste crime incorreria quem atribuísse "falsamente a alguém, mediante o uso do nome, pseudônimo ou sinal por ele adotado para designar seus trabalhos, a autoria de obra literária".

Cuidava-se, como se vê, não de verdadeira proteção ao nome, mas de proteção ao direito autoral. Posteriormente, esse equívoco legislativo foi corrigido com a Lei $\mathrm{n}^{\circ}$. 10.695/03, suprimindo-se esse tipo penal.

Há, ainda, o caso do tipo de falsa identidade, previsto no artigo 307 do Código Penal. No entanto, aqui também não há propriamente uma proteção ao nome, mas apenas uma punição a quem não utilizar de seu próprio nome para identificar-se. Privilegia-se, assim, somente o aspecto publicístico do nome, mas não o seu aspecto privado.

O mesmo raciocínio aplica-se ao tipo previsto no artigo 309 do CPB (fraude de lei sobre estrangeiro). Nesse tipo, prevê-se ser crime "usar o estrangeiro, para entrar ou permanecer no território nacional, nome que não é o seu". Novamente aqui se sobressai o interesse público, sem que se manifeste qualquer proteção ao nome no aspecto privado.

Talvez o dispositivo que mais toque ao direito ao nome no âmbito penal seja o tipo que descreve a falsidade ideológica. Previsto no art. 299 do Código Penal, cometerá crime aquele que "Omitir, em documento público ou particular, declaração que dele devia constar, ou nele inserir ou fazer inserir declaração falsa ou diversa da que devia ser escrita, com o fim de prejudicar direito, criar obrigação ou alterar a verdade sobre fato juridicamente relevante". Para isso, a lei comina pela pena de reclusão, de um a cinco anos, e multa, se o documento é público, e reclusão de um a três anos, e multa, se o documento é particular". Mas há mais. O parágrafo único estabelece que "se o agente é funcionário público, e comete o crime prevalecendo-se do cargo, ou se a falsificação ou alteração é de assentamento de registro civil, aumenta-se a pena de sexta parte".

Ou seja: quando a falsidade ideológica implicar falsificação ou alteração do registro civil, o legislador estabelece uma causa de aumento da pena. Ressalta-se, portanto, a maior ofensa ao bem jurídico tutelado (a fé pública) quando presente esta causa de aumento, cominando-se pena maior do que a normal para o delito.

No que toca ao aspecto civil, a proteção é mais ampla.

Em relação ao aspecto publicístico, a proteção está dada com a regra geral de imutabilidade do nome (Planiol e Ripert, 1925, p. 101). Somente nas hipóteses legais pode-se alterar o nome de registro, assegurando-se uma perfeita individualização dos sujeitos.

No seu aspecto privatístico, o próprio Código Civil estabelece, em seu art. 17, que "o nome da pessoa não pode ser empregado por outrem em publicações ou representações que a exponham ao desprezo público, ainda quando não haja intenção difamatória". Desse modo, aquele que tiver seu nome veiculado em publicações ou representações sem sua devida autorização, poderá acionar judicialmente quem o veiculou.

No entanto, convém destacar que, como tudo na ordem jurídica, esse direito não é absoluto. Há de sopesar-se sua aplicação no caso concreto para que não se conduza o 
intérprete a conclusões absurdas. Por exemplo: um político que tenha seu nome associado a um rumoroso caso de corrupção. É evidente que se trata de um fato jornalístico. Portanto, merece a atenção da imprensa, e é dever dela dar conhecimento do fato ao distinto público. É fato, também, que a própria Constituição Federal assegura expressamente a liberdade de imprensa (art. 220, caput, GF/88), vedando qualquer forma de embaraço ou censura ao seu exercício. Desse modo, o político em questão jamais poderia, sob o pretexto de inexistência de autorização, buscar judicialmente proibir a circulação de revistas e jornais que noticiassem o fato (Viana e Monteiro, 2009, p. 51).

Outra hipótese prevista no Código Civil acerca da proteção ao nome diz respeito à imposição de que, "sem autorização, não se pode usar o nome alheio em propaganda comercial" (art. 18).

Aqui, à diferença do que ocorre no art. 17, tem-se uma proteção mais ampla. Com efeito, é dificil imaginar que alguém possa, sem autorização, utilizar licitamente o nome de outrem para promover determinado produto ou serviço. Ainda que se trate de produto ou serviço de renome, ainda que se imagine que o produtor ou fornecedor poderia pagar vasta soma em dinheiro pela utilização do nome veiculado, o titular do nome pode, potestativamente, não querer ver seu nome vinculado a nada, por maior que seja a recompensa em pecúnia. Trata-se de direito potestativo do sujeito: é dado a ele - e somente a ele - decidir se aceita ou não ter seu nome veiculado a certa propaganda comercial.

Também aqui, à diferença do artigo anterior, pode-se pensar que o sujeito que tenha seu nome vinculado indevidamente poderia pleitear judicialmente a suspensão da veiculação da propaganda, além, é claro, de indenização pela sua utilização indevida (Viana e Monteiro, 2009, p. 52).

Destaque-se, ainda, que a proteção jurídica do nome engloba não somente este em sentido estrito. Também os pseudônimos gozam da mesma proteção. É o que infere do art. 19 do Novo Código, quando afirma que "o pseudônimo adotado para atividades ilícitas goza da proteção que se dá ao nome".

Exemplificativamente, pode ser que pouco efeito comercial tenha a vinculação de determinado suplemento alimentar ao fato de um certo "Edson" consumi-lo. Entretanto, a questão muda de figura quando esse mesmo produto é definido como "o suplemento que o Pelé usa".

É importante destacar, no entanto, que a proteção ao pseudônimo somente se dá quando sua violação ocorrer dentro do mesmo ramo de atividade (Carvalho, 1972, p. 71). Há casos em que um pseudônimo é idêntico a outro, embora seus portadores sejam pessoas diferentes. Um caso emblemático é o de "Xuxa", apelido originalmente designativo de uma apresentadora de televisão, mas hoje também alcunha conhecida de um famoso nadador brasileiro. Embora o pseudônimo deste tenha se originado do primeiro, é evidente que a apresentadora de televisão não poderá promover ação contra o nadador por ter usado o seu pseudônimo na promoção de um material esportivo qualquer. 
Todavia, o ordenamento pátrio ressente-se de uma tutela mais detalhada e específica, destinada a coibir eventuais violações ao direito ao nome. Assim como aos demais direitos de personalidade, deveria ser dispensada maior atenção do legislador, impedindo-se que todas as questões resolvam-se somente pela invocação de princípios da ordem constitucional.

Poder-se-ia pensar, de lege ferenda, em alterar-se a redação do artigo 17 do Código Civil, para englobar não só os casos em que a reprodução ou emprego do nome alheio exponha ao desprezo público. Conviria alargar o dispositivo legal para todo e qualquer caso em que o uso do nome alheio dê-se de forma abusiva.

Mas, a despeito de eventuais omissões, pode-se dizer que o novo paradigma estabelecido pelo Novo Código Civil tem o mérito de positivar o direito ao nome como direito da personalidade e representa um primeiro passo em direção à excelência no tratamento dogmático da matéria.

\section{REFERÊNCIAS}

BAUDRY-LANCATINERIE, G.; HOUQUES-FOURCADE, M. Traité Théoriqueet Pratique de Droit Civil. 3. ed. Paris: Sirey, 1907.

CAPELO DE SOUSA, Rabindranath Valentino Aleixo. O Direito Geral de Personalidade Coimbra: Coimbra, 1995.

GARVAlHO, Manuel Vilhena de. Do Direito ao Nome - Protecção Jurídica e Regulamentação legal. Coimbra: Almedina,1972.

COELHO, Luís Pinto. Direito Civil. Lisboa: AAFDL, 1953.

DE GUPIS, Adriano. I Diritti della Personalità. Milano: Giuffrè, 1950.

DRAY, Guilherme Machado. Direitos dePersonalidade Coimbra: Almedina, 2006. FIÚZA, César. Direito Civil. 10. ed. Belo Horizonte: Del Rey, 2007.

GONÇALVES, Luiz da Cunha. Tratado de Direito Civil. v. I. Coimbra: Coimbra, 1929.

PEREIRA, Caio Mário da Silva. Instituições de Direito Civil. v. I. Forense: Rio de Janeiro, 1998.

PLANIOL, Marcel; RIPERT, George. Traité Pratique de Droit Civil Français. Paris: Librairie Générale de Droit et de Jurisprudence, 1925.

PONTES DE MIRANDA, Francisco Cavalcanti. Tratado de Direito Privado. t. I. Campinas: Bookseller, 2000.

RAYNAUD, Pierre. Les Personnes. Paris: Sirey, 1976. 
VENOSA, Sílvio de Salvo. Direito Civil - Parte Geral. v. I. 6. ed. São Paulo: Atlas, 2006. VIANA,Juvêncio Vasconcelos; MONTEIRO, Arthur Maximus. Direitos da personalidade e sua tutela processual. Revista Dialética de Direito Processual. no. 77, p.46-61, ago/2009.

VOIRIN, Pierre. Manuel de Droit Civil - Tome I. 17. ed. Paris: Librairie Générale de Droit et Jurisprudence, 1970.

\section{THE LEGAL PROTECTION OF THE NAME OF THE NATURAL PERSON IN BRAZI LIAN LAW}

Abstract: In this article we will try to analyze the main aspects related to the name of the natural person in Brazil. The first problem concerns the very definition of the matter: what is meant by the right to a name? Departing related figures that have the same origin - the personality - the research focus on an examination of the dogmatic issue. It will be defined: (1) the constituent parts of the name; (2) what is meant by pseudonym; (3) what is the legal protection given to the name by our legal system, whether in the criminal or in the civil area.

Keywords: Private Law. Rights of Personality. Right to a Name. 